Investigaciones Fenomenológicas, n. 10, 2013, 209-223.

e-ISSN: $1885-1088$

\title{
PONER LAS COSAS EN SU LUGAR.
}

\author{
Comentario a Javier San Martín,
}

LA fENOMENOLOGÍA DE ORTEGA Y GASSET,

MADRID, Biblioteca NueVA, 2012, 217 PP.

María Lida Mollo

Università degli Studi di Napoli Federico II, Italia maria.lida.mollo@hotmail.it

"Poner las cosas en su lugar". Es sin lugar a duda éste el intento que motiva las páginas de uno de los más autorizados intérpretes del pensamiento orteguiano cuando decide escribir La fenomenología de Ortega y Gasset. Con dicho título, en efecto, Javier San Martín exhibe de antemano la voluntad de abordar más que una cuestión, la del modo orteguiano de declinar la fenomenología husserliana, un enjambre de cuestiones: la fenomenología como etapa formativa y liberatoria del neokantismo de Marburg, la recepción de Logische Untersuchungen e Ideen I, el impulso que la Escuela de Madrid da a las primeras tesis de doctorado y a las primeras traducciones de Husserl (bástenos referirnos a Gaos y a Zubiri), las correcciones y las integraciones propuestas a la fenomenología, los malentendidos y las ambigüedades concernientes nada menos que a la epojé y a la reducción trascendental, las diversas visiones de Husserl, que en la mayoría de los casos proceden de la falta de comprensión de la complementariedad entre método estático y genético, el encuentro con la Krisis que Ortega atribuye erróneamente a Fink ${ }^{1}$ y, sobre todo, la fenomenología como clave de

\footnotetext{
${ }^{1}$ Imposible no remitir a J. San Martín, Para una filosofía de Europa. Ensayos de fenomenología de la historia, Madrid, Biblioteca Nueva-UNED, 2007, en especial el parágrafo 1 "Fechas para la génesis de $L a$
} 
lectura de la obra orteguiana que no se agota en los así llamados escritos fenomenológicos y que no se detiene en la fatídica fecha de $1929^{2}$.

Ya desde este escueto resumen de algunos de los núcleos temáticos de uno de los últimos libros de San Martín resulta claro cuán lejos el Autor ha ido de las clásicas interpretaciones de Ortega, en buena parte basadas en lo que el pensador del Escorial decía de sí mismo. Lo cual significa no aceptar la posición de quien, como Julián Marías y Antonio Rodríguez Huéscar, con Ortega mantenía un estrecho contacto precisamente en esos años cruciales (desde el año 1929 en adelante) en los que el abandono de la fenomenología parecía haberse vuelto improrrogable para quien había forjado una teoría, la del yo ejecutivo, en abierto contraste con toda forma de idealismo, incluso con el que se había revelado ya no más "metódico", tal como había sido calificado en la reseña a Hoffmann de 1913 titulada Sobre el concepto de sensación, sino real o metafísico.

Pero no es todo. Por el tamiz de la crítica pasan tanto las declaraciones de ruptura con la "buena suerte" de la fenomenología pronunciadas desde 1929 en adelante como la mirada retrospectiva que Ortega echa sobre su propio itinerario intelectual, de la que Prólogo para alemanes constituye un caso emblemático. Otro caso es cuando se trata de reivindicar, sin más dilaciones y renuencias, "el nivel de nuestro radicalismo", de un radicalismo que Ortega sitúa ya en Meditaciones del Quijote, es decir en el contexto en el que el hiperfenómeno había sido precozmente captado no en la conciencia como horizonte de vivencias sino en la vida en tanto que fenómeno sistemático de cuyo análisis había que partir. Hasta el punto de que en La idea de principio en Leibniz y la evolución de la teoría deductiva, de 1947, Ortega asegura haber abandonado la fenomenología en el momento mismo de recibirla ${ }^{3}$.

Tal afirmación no podía sino tener importantes repercusiones, sobre todo si se considera que los años de recepción de la fenomenología son los mismos en

crisis de las ciencias europeas" del cap. X, en el que San Martín muestra la continuidad de la que goza la unión de la razón teórica con la razón práctica en el itinerario husserliano así como los motivos que hacen que el tema de la historia adquiera centralidad conjuntamente a la definición del proyecto de Europa "en un mundo en el que ese proyecto parece sucumbir totalmente" (p. 243).

${ }^{2}$ Cf. J. Ortega y Gasset, ¿Qué es filosofía?, en OC, vol. VIII, Madrid, Taurus, 2008, p. 225: "La fenomenología, al describir un acto, elimina, reduce su carácter ejecutivo. Nosotros nos ocupamos exclusivamente de éste. No tomamos el acto según aparece como objeto en la reflexión, sino que, al revés, dejamos en suspenso nuestra reflexión - ya que ésta es forzosa".

3 J. Ortega y Gasset, La idea de principio en Leibniz y la evolución de la teoría deductiva, en OC, vol. IX, Madrid, Taurus, 2009, p. 1119. 
los que Ortega ajusta cuentas con el neokantismo marburgués. Cuentas que parecen no saldarse o que mejor dicho jalonan la marcha de una literatura secundaria que, a un cuarto de siglo de la muerte de Ortega, todavía no disponía de textos que inmediatamente después se habrían revelado decisivos. Decisivos y demoledores de algunas de las tesis de Nelson Orringer, el autor de un libro, por cierto sumamente valioso, que tanto en el título, Ortega y sus fuentes germánicas, como en la finalidad y el método - "un ejercicio de hermenéutica", "la aclaración de textos por medio de la minuciosa comparación"4 - declara preliminarmente el cauteloso intento de evitar interpretaciones forzadas con la humilde, paciente y laboriosa inmersión en los más de veinte mil volúmenes que constituían una de las circunstancias más íntimas de Ortega: su biblioteca. Lo correcta que luego se habría revelado para esta última la idea de que la circunstancia es tanto medio como barrera, tanto ventaja como desventaja, tanto sólida tierra como tierra que se raja y se quiebra y en consecuencia duda líquida y naufragio, lo demuestra un simple evento editorial: la publicación a cargo de Paulino Garagorri de Investigaciones psicológicas que obligan a Orringer a revisar la tesis según la cual Ortega habría tomado distancia de la fenomenología, y lo habría hecho en la temprana fecha de 1914, en especial en Ensayo de Estética a manera de prólogo, bajo la influencia de Natorp, que, como es notorio, había expresado en su Allgemeine Psychologie de $1912^{5}$ significativos disensos respecto de las Logische Untersuchungen que - según pone de manifiesto Orringer - concernían ante todo el empleo husserliano del verbo vollziehen, "ejecutar", un empleo que reflejaba una idea de conciencia asumida "en su actividad acostumbrada de convertir las vivencias en objetos, de alejarlas del yo, de objetivarlas" ${ }^{\prime \prime}$.

Que la confrontación Husserl-Natorp haya sido particularmente provechosa lo demuestran escritos como Die Idee der Phänomenologie, donde Husserl expone un proyecto de trascendental con vocaciones constitutivas en lugar de constructivistas, pero también la reseña de Natorp a Ideen $I^{7}$, en la que la críti-

\footnotetext{
${ }^{4}$ N. Orringer, Ortega y sus fuentes germánicas, Madrid, Gredos, 1979, p. 13.

${ }^{5}$ P. Natorp, Allgemeine Psychologie nach kritischer Methode, vol. I, Objekt und Methode der Psychologie, Tübingen, Mohr, 1912.

${ }^{6}$ N. Orringer, Ortega y sus fuentes germánicas, p. 85.

7 P. Natorp, Husserls "Ideen zu einer reinen Phänomenologie", en Die Geisteswissenschaften, 1913/1914, Heft 16, 15 de enero de 1914, pp. 420-426 y Heft 17, 22 de enero de 1914, pp. 448-451; posteriormente reeditada en Logos. Internazionale Zeitschrift für Philosophie der Kultur, Band 7, 1917/1918, pp. 224-246.
} 
ca que anteriormente había sido dirigida a las Logische Untersuchungen, es decir la crítica de haber reducido la subjetividad a una "segunda objetividad" habría cedido el paso a la asunción de la bilateralidad de la conciencia ${ }^{8}$.

La "heterogénesis" de los fines reside en que Ortega, a juicio de Orringer, habría superado a Husserl gracias al maestro Natorp precisamente cuando éste había recalibrado su posición ante la fenomenología. Pero entonces hay algo que Ortega no acepta, algo que es también la herencia neokantiana de la que advierte la urgencia de liberarse y que no es otra cosa que la conciencia. Se comprende cómo en un libro que ha hecho historia en la crítica, como La voluntad de aventura, de Pedro Cerezo Galán, se llegue a hablar de una "neutralización recíproca" ${ }^{9}$ por la que cada uno de los dos idealismos frecuentados por Ortega implicaba la negación de un supuesto del otro. Sin embargo, es un hecho que, por cuanto recíproca, la neutralización le resulta asimétrica al propio Cerezo. Es más, es precisamente en esta asimetría que se basa el mérito de un libro que, a diferencia de los que le anteceden - incluso de los inmediatamente antecedentes - dispone de la edición de Garagorri, que quiere decir disponer de los textos que muestran inequívocamente la limitación de la tesis según la cual Ortega se habría liberado de la fenomenología en los primeros años diez, es decir en esos mismos años en los que las Investigaciones lógicas constituyen una de las fuentes principales de las reflexiones acerca del significado, así como las Ideas proporcionan, entre los no pocos malentendidos concernientes nada menos que a la confusión entre fenómeno y esencia ${ }^{10}$, la posibilidad de pasar

\footnotetext{
${ }^{8}$ N. Orringer, Ortega y sus fuentes germánicas, cit., p. 88: "Natorp [...] sostiene que la conciencia es bilateral, que apunta hacia fuera, hacia su contenido y, al mismo tiempo, hacia dentro, hacia el yo. Luego puede aceptar la doctrina de Husserl de que, durante la reducción fenomenológica, parte de la atención vuelve sobre sí misma para contemplar, de manera introspectiva, la otra parte, dirigida hacia el exterior y ocupada en afirmar el ser del mundo. La reflexión hacia dentro, escribe Natorp, no objetiva el acto afirmativo, no convierte en objeto el acto de poner el ser, pues no separa este acto de la vivencia bajo examen fenomenológico". Sin embargo el propio Natorp señala una radical divergencia entre quien, como Husserl, considera que la conciencia pura se da absolutamente a través de la suspensión del acto de la posición objetiva y él mismo que asevera que "reconstruirla" es una tarea específica y compleja que requiere de un método perfectamente simétrico al de la objetivación que abre una vía que va hacia el infinito (Cf. P. Natorp, Husserls "Ideen zu einer reinen Phänomenologie", en Logos. Internazionale Zeitschrift für Philosophie der Kultur, Band 7, 1917/1918, p. 236). Es digno de atención que Natorp concluya su reseña exhibiendo una obstinada armonía. Pues la diferencia tan radical antes mencionada parecería disolverse ante la idea que Natorp, haciendo hincapié en el nexo de reciprocidad entre noesis y noema (cualquier mínima diferencia por el lado noemático remite eidéticamente a la mínima diferencia por el lado noético), declara compartir con Husserl, es decir la idea de una "subjetivación" (en términos natorpianos) que, al igual que la objetivación, se configura como una "tarea infinita" (ibid., p. 245).

${ }^{9}$ P. Cerezo Galán, La voluntad de aventura, Barcelona, Ariel, 1984, p. 202.

10 J. Ortega y Gasset, Sobre el concepto de sensación, en OC, vol. I, Madrid, Taurus, 2004, pp. 630-631: "Mi acto de visión de la mesa transcurre: la mesa material motivo de mi visión se corrompe, pero el objeto 'mesa que yo he visto ahora' es incorruptible y exento de vicisitudes. Tal vez mi recuerdo de él sea torpe y confuso, pero la mesa que vi, tal y como la vi, constituye un objeto puro e idéntico a sí mis-
} 
"del valor ejecutivo de las cosas" a una "actitud espectacular y descriptiva". De la trama de cuestiones y de fuentes que se entrelazan en el término "ejecutivo" trataremos más adelante, y ello porque una de los aportaciones más importantes de San Martín atañe, en esta como en otras obras suyas, al descubrimiento del significado y del contexto del que Ortega extrae un concepto que funge como piedra de toque de su raciovitalismo.

Pero por ahora regresemos a Cerezo, puesto que justamente dialogando con el pensador de Granada, San Martín no sólo desenreda el nudo epojéreducción trascendental, sino que también reivindica la permanencia en Ortega de la instancia trascendentalista. En virtud de la fenomenología, en especial gracias al valioso instrumento de la intuición categorial, Ortega habría superado, según Cerezo, el constructivismo neokantiano con todos sus defectos: culturalismo, epistemología sin mordiente ontológica, tendencia a un pensar normativo más que inventivo ${ }^{11}$. A la hora de señalar la vertiente neokantiana a la que le habría tocado la común suerte de ser neutralizada por ese "instinto de realidad" que llevaría a Ortega a rastrear supuestos subjetivistas tanto de un lado como de otro, Cerezo Galán hace referencia a un pasaje de la lección XV de Sistema de la psicología. Dicha lección parte del problema del significado, de la dificultad de dar cuenta de otro grado del ver: "Si yo veo en el encerado el signo 'tierra' - expresemos paradójicamente lo que paradójico es -, no veo lo que propiamente veo - la línea blanca del yeso que ondula sobre el negro -, sino que aún más que eso, y como puesta y montada sobre eso, veo una 'significación'"'12. De ahí Ortega destaca los dos valores del ver: ver como sensación

mo. No es un objeto individual, es una esencia. La intuición individual, la llamada experiencia, puede convertirse siempre en intuición esencial". Muy distinta habría sido la definición de fenómeno y de esencia en un texto de 1929 titulado Sobre la fenomenología cuyo incipit es "siempre he admirado la decisión con que Eugenio d'Ors habla de las cosas que desconoce". Pero más allá de la ironía con la que Ortega se divierte en criticar a D'Ors, merece la pena transcribir el párrafo en el que por fin queda aclarada la distinción entre fenómeno y esencia: "En cuanto puro fenómeno, 'esta mesa negra', con su tiempo y espacio, es ya invariable e indestructible. Sin embargo, el puro fenómeno que ahora es la mesa negra percibida no es ni de lejos una esencia. Si así fuese, si los objetos de las percepciones fuesen en algún sentido esencias, holgaba la fenomenología, la filosofía, las ciencias todas y el pensamiento. Mirar sería una operación apodíctica. Mas no hay tal. Del puro fenómeno que es la mesa vista tengo que extraer su esencia, del individuo alquitarar el eidos, el cual es siempre general, como todo el mundo, salvo el señor Ors, sospecha, malicia o columbra. Si este señor hubiese movilizado mínimamente su intelecto cuando escribía, hubiera reparado en la estolidez que es considerar la combinación de notas "mesa negra" como algo esencial". Es más, la cita de la p. 10 de la primera edición de Ideen (ya presente en la reseña al texto de Hoffmann) ahora (después de dieciséis años) responde al intento de poner de manifiesto la distinción entre fenómeno y esencia: "No más que en la página décima de su libro dice Husserl: 'La esencia (eidos) es un objeto de nueva especie. Y así como lo dado en la intuición individual o empírica es un objeto individual, así lo dado en la intuición de esencias es una pura esencia'"' (OC, vol. VIII, p. 184).

${ }^{11}$ P. Cerezo Galán, La voluntad de aventura, cit., p. 204.

12 J. Ortega y Gasset, Sistema de la psicología, en OC, vol. VII, Madrid, Taurus, 2007, p. 528. 
y ver como percepción. "Yo percibo las cosas y en ellas, como su faz y su propiedad, los colores: esos son los que llamaremos, pues, los colores objetivos porque son del objeto y en él están"13. El significado a la par de un color entonces. Con la intención de defenderse de la eventual objeción de un exponente de la psicología tradicional que protestara ante la posibilidad de equiparar los significados a los colores, Ortega alude a la filosofía neokantiana, que, si bien ha representado una auténtica fortuna en el curso de su aprendizaje, ahora que ya no se trata de aprender lo que han dicho los filósofos, sino de descubrir lo que son las cosas, se torna inviable. $Y$ ello porque si es cierto que ha llegado el momento de las cosas, entonces hay que atender a como son y no a como deben $\operatorname{ser}^{14}$.

Es en el momento en que Cerezo pasa a considerar la neutralización del por decirlo así "cuerno" husserliano cuando se inserta la crítica de San Martín. Partiendo del análisis de Ensayo de Estética a manera de prólogo, el autor de La voluntad de aventura halla una primera, por cuanto tímida, crítica de Ideen que apuntaría a la reflexión trascendental. Los dos argumentos involucrados en la crítica serían la ejecutividad y la imposibilidad de objetivar al yo. El ejemplo es la célebre vivencia del dolor. Escribía entonces Ortega: "para que yo vea mi dolor es menester que interrumpa mi situación de doliente y me convierta en un yo vidente. Este yo que ve al otro yo doliente, es ahora el yo verdadero". Pero entonces el yo doliente se ha vuelto falso, fingido, virtual, no sólo, y considerando el modo orteguiano de traducir la puntualidad de la vivencia, "pasado". "El yo doliente - según prosigue Ortega - hablando con precisión, fue, y ahora es sólo una imagen, una cosa u objeto que tengo delante" ${ }^{15}$.

Pero si Cerezo no deja de señalar la ilegitimidad de asimilar la reflexión al recuerdo, sin embargo asevera que lo que constituye el objeto de la crítica es la connotación trascendentalista de la reflexión, por cierto no esta última de la que no se puede sino reconocer la centralidad, si bien dentro de una figura elíptica cuyo otro centro es la vida y cuyo movimiento más propio es des-vivirse, "en la doble acepción de dejar de vivir y de aprestarse a mejor vivir"16. Pero hay más. La reflexión como "complemento y antítesis de la vida en ejecución

${ }^{13}$ Ibid., p. 529.

${ }^{14}$ Ibidem.

15 J. Ortega y Gasset, Ensayo de Estética a manera de prólogo, en OC, vol. I, p. 669.

${ }^{16}$ P. Cerezo Galán, La voluntad de aventura, cit., p. 254. 
atraviesa de una punta a otra la obra de Ortega, al menos mientras estuvo bajo la influencia directa de Husserl" ${ }^{17}$, que, según Cerezo, alcanza hasta 19291930.

Ahora bien, después de haber reconocido el valor de una obra, como la de Cerezo, que ha representado una suerte de brújula, hasta el punto de que San Martín considera las obras que le han sucedido, comenzando por la propia, como una "ampliación o profundización" ${ }^{18}$ de La voluntad de aventura, llega el momento de la desconstrucción que, por cuanto respetuosa, toca dos puntos capitales: uno cronológico, pero como resulta evidente no solamente cronológico, concerniente a la datación de la cercanía con la fenomenología husserliana, que, como ya ha sido visto, a juicio de San Martín acompaña el itinerario orteguiano mucho después del año 1929, no pudiendo entonces decaer, según parece pensar Cerezo, cuando en ¿Qué es filosofía? Ortega se apropia de las críticas schelerianas y heideggerianas dirigidas a la epojé. En realidad, según advierte San Martín, es el propio Cerezo quien desplaza la fecha más allá de 1929, y ello por la simple razón de que a la hora de abordar el problema del "mundo", se detiene en una obra tardía como El hombre y la gente.

La segunda crítica apunta a la confusión entre el proceso y el resultado, entre la epojé y la reducción trascendental. "Algunos de los problemas que podríamos encontrar en la exégesis de Pedro Cerezo están en relación con la identificación entre epojé y reducción, usual en los que no se han adentrado en lo que se llama el 'nuevo' Husserl. En El tema de nuestro tiempo están presentes los dos conceptos en su sentido preciso: lo que Cerezo expone con precisión es el concepto de epojé, y de eso tenemos una muy buena descripción en el último capítulo de El tema de nuestro tiempo, cuando se habla de la 'conversión' del mundo cósmico en un mundo vital. Esa es la reducción. Con esta diferencia podríamos seguramente aclarar algunas dificultades que presenta la relación de Ortega con la fenomenología" ${ }^{19}$.

Una confusión que está estrechamente relacionada con la dúplice virtualidad que Ortega atribuye a la metáfora. En Ensayo de Estética a manera de prólogo queda destacado el doble significado de la metáfora como "un procedi-

\footnotetext{
${ }^{17}$ Ibidem.

${ }^{18}$ Infra, p. 29.

${ }^{19}$ Infra, p. 33.
} 
miento y un resultado, una forma de actividad mental y el objeto mediante ella logrado"20. Refiriéndose una vez más a la epojé, San Martín señala que en la recepción de Ideas I, Ortega confundió en la reseña al escrito de Heinrich Hoffmann Untersuchungen über den Empfindungsbegriff "la tesis de la actitud natural, la eficacia ejecutiva o tética de los actos de acuerdo con las Ideas, con el vivir ejecutivamente de las Investigaciones lógicas" ${ }^{21}$. A más de esto, respecto del trascendentalismo, San Martín está convencido, y no desde ahora, que entender la tesis de la actitud natural a partir del valor ejecutivo equivale a afirmar una subjetividad insertada en un mundo real "que sólo es real en la medida en que me es". De esta íntima correlación, del carácter tético de la experiencia se deriva el sentido de la epojé. La tesis de la actitud natural sería entonces - y en contraste con la literatura crítica tradicional - "un descubrimiento de grueso calibre trascendental"22.

Regresemos a Ortega, reactualizando los recuerdos de una relación, la relación con la fenomenología, que según él dice, se habría truncado aún antes de comenzar. Ortega recuerda ${ }^{23}$ haber enunciado explícitamente su propio tema, ya en el año '25, como una renovación desde las raíces del problema tradicional del Ser, renovación que habría sí hallado en el método fenomenológico una vía certera, un camino seguro - o mejor dicho la euporía que habría impedido que la aporía se transformara en desesperación - pero sólo después de haberlo dotado de la dimensión de un pensar sistemático.

Sistemático y no desesperado entonces. Sin embargo, en la conferencia Sensación, construcción e intuición - contemporánea de la reseña a Hoffmann, que, vale la pena recordarlo, se ha merecido un capítulo entero de Ensayos sobre Ortega, no casualmente titulado "El primer texto de fenomenología en español"24 - Ortega había entendido el radicalismo como ausencia de supuestos. Una ausencia, o mejor dicho una indigencia, que parecía hacer hincapié más en la duda que en el método, o que por lo menos connotaba la asunción de la duda, como punto de Arquímedes de la investigación, con un tono dramático: "la filosofía nace, por consiguiente, en una situación desesperada. Tiene, por decir-

\footnotetext{
20 J. Ortega y Gasset, Ensayo de Estética a manera de prólogo, en OC, vol. I, p. 673.

${ }^{21}$ J. San Martín, Ensayos sobre Ortega, Madrid, UNED, 1994, p. 245.

22 J. San Martín, Fenomenología y cultura en Ortega, Madrid, Tecnos, 1998, p. 129.

${ }^{23}$ J. Ortega y Gasset, La idea de principio en Leibniz y la evolución de la teoría deductiva, en OC, vol. IX, p. 1119.

${ }^{24}$ J. San Martín, Ensayos sobre Ortega, cit., pp. 161-246.
} 
lo así, que ganarse la vida desde la cuna. De aquí su radicalismo. No se le permite apoyarse en capital ni herencia alguna de certidumbres, de verdades adquiridas $^{\prime 25}$. Si bien este pasaje aparece inmediatamente después de una referencia a Descartes y si bien se sitúa en un texto en que es precisamente la intuición, la husserliana Anschauung, lo que funge de antídoto contra el constructivismo neokantiano como contra el empirismo que no se percata de ser constructivista cuando apunta por ejemplo al "puro sonido", sin embargo dicho pasaje parece ser más afín al Banquete que al Discurso del método o a Ideas. Y ello porque más que hablar de aporía o de euporía, Ortega parece evocar a la Penía que fue madre de Eros.

Lo cual no contradice mínimamente la convicción de San Martín según la cual en la primera década, en especial en un texto en el que se insta a ser el amante más que el juez de las cosas, Meditaciones del Quijote, Ortega adoptó la fenomenología declinándola en una filosofía de la percepción y de la cultura animada por la tensión sensaciones materiales-sentido virtual. Merece ser destacado que a la hora de analizar las aportaciones orteguianas a la fenomenología, San Martín hace hincapié en un dato de inestimable valor, que por otra parte ya había sido indicado por Nelson Orringer como una de las fuentes germánicas principales $^{26}$ : el conocimiento por parte de Ortega de la fenomenología de la percepción de Wilhelm Schapp, en especial de los Beiträge zur Phänomenologie der Wahrnehmung, en los que el propio Schapp admite no estar en condiciones de distinguir lo que es suyo y lo que es de su maestro y director de tesis Husserl. La fuente de Schapp es importante porque éste había concurrido a las lecciones de 1907 acerca de Ding und Raum, a las que Husserl quiso anteponer la exposición de Die Idee der Phänomenologie, donde por primera vez aparece mencionada la epojé. Lo cual significa que si se desea seguir hablando de "giro trascendental", Ortega tiene noticia de dicho giro aún antes de leer Ideen I.

No queriendo dejar desatendida la tarea de enfrentar la pluralidad de niveles y de dificultades que una expresión aparentemente inocua y por así decirlo gráfica como "puesta entre paréntesis" ha podido comportar para Ortega y sus intérpretes, antes hay que detenerse en lo que San Martín considera como la principal aportación de Ortega: la idea según la cual la percepción humana es

\footnotetext{
25 J. Ortega y Gasset, Sensación, construcción e intuición, en OC, vol. I, p. 643.

${ }^{26}$ Cf. N. Orringer, Ortega y sus fuentes germánicas, cit., pp. 133-168.
} 
una percepción cultural y "la cultura no es sino el conjunto de ese sentido por el cual percibimos las cosas y el mundo"27. Pero si el meollo de las Meditaciones cuyo origen, no se lo olvide, había sido justamente la disputa entre Unamuno y Ortega acerca del sentido de la cultura europea - reside en haber situado el objeto de la percepción en el contexto vital dentro del cual adquiere sentido, entonces la afirmación anticartesiana según la cual "el mundo no es ni materia ni alma sino una perspectiva" debe ser reinterpretada. Y ello porque - según escribe San Martín - "no se ha reparado en el sentido cultural de esa 'perspectiva', con lo que ha quedado desactivada, pues normalmente se ha considerado esa perspectiva como una perspectiva espacial, lo que también es cierto, pero más allá de esa perspectiva espacial, que es animal, el mundo incluye la perspectiva del sentido en el que el mundo es percibido, y que ya es humana" ${ }^{28}$.

Que Ortega haya identificado el ámbito del sentido con el ámbito de lo virtual y que éste último haya sido confiado al arte es ciertamente una manera típicamente española de valorar lo que se tiene: la perla del Quijote y dos excepciones, dos pintores prodigiosos de un pueblo "mal dotado para la pintura", tal como resulta del Preludio a un Goya de $1946^{29}$. Que la interpretación de las artes figurativas esté estrechamente relacionada y condicionada por las diversas etapas del itinerario orteguiano lo demuestra el nexo entre neokantismo y la defensa de Zuloaga, pero también la hermenéutica fenomenológica de Velázquez y Goya, quienes dieron muestra de servirse de los elementos del mundo real como alimento de "fantasmas lumínicos" y de Pinturas negras. Aún antes, se trataba de "salvar lo virtual" de las cuevas de Altamira, que contradecía la teoría de Worringer expresada en Formprobleme der Gotik ${ }^{30}$ según la cual la evolución del arte sería paralela a la evolución de la persona humana, y por tanto partiría de líneas geométricas y sólo en un momento ulterior estaría caracterizada por el realismo. Ortega, criticando a Worringer por haber considerado el arte español como el residuo de un imitativismo infantil, asevera que

\footnotetext{
${ }^{27}$ Infra, p. 178.

${ }^{28}$ Ibidem.

29 J. Ortega y Gasset, Preludio a un Goya (1946), en OC, vol. IX, p. 763.

${ }^{30}$ W. Worringer, Formprobleme der Gotik, Múnich, Piper Verlag, 1911; trad. cast. de M. García Morente, La esencia del arte gótico, Madrid, Revista de Occidente, 1925.
} 
"en el arte español se anunciaría una emoción propia ante el mundo, lo que él va a llamar el mediterranismo" ${ }^{31}$.

De todos modos San Martín pone de manifiesto que el recurso a la declinación artística de lo virtual no es solamente una cuestión de estilo mediterráneo, sino de un momento específico del itinerario orteguiano, es decir cuando Ortega todavía no ha alcanzado una teoría acerca del cuerpo que le permita plantear correctamente el tema de la percepción. "La fenomenología le descubrirá a Ortega que ese mundo virtual no es algo que se nos dé sólo en el arte, sino que lo virtual está enraizado en la realidad humana misma, más aún, lo fundamental de la realidad humana está constituido por un elemento virtual, a saber, el sentido"${ }^{\prime 32}$.

Los elementos que conspiran en la elaboración de una teoría acerca de la percepción, cuyos primeros bosquejos anteceden, tal como lo comprueba San Martín, la lectura de Ideen I, no conciernen solamente a una concepción en formación de lo virtual, sino también de lo ejecutivo. Sobre este último San Martín señala la falta de coherencia entre dos textos contemporáneos cuales Meditaciones del Quijote y Ensayo de Estética a manera de prólogo. El pasaje en cuestión, presente no sólo en el Ensayo sino también en la reseña a Hoffmann del '13 y aún antes en una conferencia de 1912 titulada La "idea" de Platón, afirma la no coincidencia entre lo ejecutivo y lo virtual, entre el sol que veo y el sol que quema (La "idea" de Platón, Sobre el concepto de sensación) entre un "dolor de que se me habla y un dolor que yo siento" puesto que "el dolor doliendo es lo contrario de su imagen: en el momento que se hace imagen de sí mismo deja de doler" ${ }^{\prime 33}$. Y es precisamente la forma con la que dicha incoincidencia (si de incoincidencia se trata) debe ser entendida lo que impulsa a San Martín a denunciar resabios neokantianos y además la omisión de un

\footnotetext{
${ }^{31}$ Infra, p. 76. Cf. J. Ortega y Gasset, Arte de este mundo y del otro, en OC, vol. I, p. 445: "Los artistas españoles que hace tres mil años cubrieron las paredes de una caverna con figuras de bisontes - propiamente urus o toros de Europa - aspiran a abrir la historia del arte. Y el caso es que su obra rezuma al través de los milenios un realismo agresivo y vencedor. Los toros magníficos, de hinchada cerviz y testuz crinada, aquellos soberbios cuadrúpedos cuya vista maravilló a César cuando entró en Aquitania, y de que hoy subsisten sólo unos cuantos centenares recluidos en dos fincas del zar ruso, perviven inmortalizados por manos certeras, guiadas por corazones amantes desaforados de lo real en el fresco prehistórico de Altamira".

${ }^{32}$ Infra, p. 180.

33 J. Ortega y Gasset, Ensayo de Estética a manera de prólogo, en OC, vol. I, p. 668. Y prosigue "[la misma diferencia que hay] entre el rojo visto por mí y el estar siendo roja esta piel de la caja. Para ella el ser roja es como para mí el dolerme. Como hay un yo Fulano de Tal, hay un yo-rojo, un yo-agua y un yo-estrella" (pp. 168-169).
} 
sentido, el tacto, en cuya "operatividad" se disolvería la oposición entre imagen y cosa. "Le hubiera bastado a Ortega, primero, haberse tomado en serio la descripción husserliana de la conciencia de experiencia de las Ideas, donde aparece el valor ponente de la percepción, que lleva en sí misma la verdad originaria y la razón originaria; y, segundo, haber metido el tacto por medio, es decir, habiendo abandonado una concepción del conocimiento meramente visual, haber operado con el cuerpo"34.

La superación de tal oposición será posible cuando Ortega logre hacer "encajar" - según advierte San Martín - lo ejecutivo en lo virtual, pero no sin exponerse a fatales equívocos que convergen finalmente en la acusación de idealismo metafísico dirigida a la fenomenología. Retomemos uno de los que San Martín considera como pasajes incoherentes respecto de la teoría de la percepción de Meditaciones del Quijote que por otra parte es un buen ejemplo del papel que juega la omisión del tacto en la negación de la coincidencia entre cosa e imagen. En la reseña a Hoffmann, Ortega escoge un cuerpo cúbico remoto a nuestro tacto como ejemplo de la correlación entre, por un lado, la variación de la orientación y la distancia que se toma de un objeto y, por otro, el cambio de la forma, el tamaño, el color, que sin embargo no desvirtúa la posibilidad de percibirlo como el mismo cubo de antes. Al contrario: "La 'cosa real visual' consiste, pues, en una serie de vistas tomadas sobre la cosa con una cierta continuidad que nos representa la permanencia de un idéntico objeto. $Y$ es esencial para lo que todos entendemos por cosa real, que esa serie de vistas, es decir, de experiencias, sea literalmente infinita. No podemos agotar los puntos de vista desde los cuales cabe ver una cosa. De modo que, según Hoffmann, se trata de un concepto límite, lo que Kant llamaría una idea" ${ }^{35}$. Precisamente en una nota a la expresión "cosa real visual" como correlato de la percepción visual, Ortega distingue entre correlato del acto y objeto, entre el sentido del sol y el sol del que hablo, y ello con el fin de señalar que "el correlato de la percepción es lo percibido, no el objeto trascendente a mí" ${ }^{36}$.

Aunque ha pasado nada más que un año de la conferencia sobre La "idea" de Platón, la posición orteguiana es otra, así como resulta sensiblemente redi-

\footnotetext{
34 Infra, pp. 106-107.

35 J. Ortega y Gasset, Sobre el concepto de sensación, en OC, vol. I, pp. 636-637.

${ }^{36}$ Ibid., p. 636.
} 
mensionada la influencia neokantiana. Basta con considerar, en el recurso al motivo platónico y luego también natorpiano acerca de la imposibilidad de mirar directamente el sol - de donde surgiría la necesidad de una torsión del sol a su reflejo, del ser a un hypothémenos $\operatorname{logon}^{37}$ - un desplazamiento de términos de "imagen" a "sentido". En la conferencia de 1912 Ortega había negado rotundamente que lo que al crepúsculo vespertino vemos caer por occidente fuera el sol. Pues se trataría de nuestra imagen del sol y "el sol real, el sol res, está quieto, anclado como un pontón dentro de los libros de astronomía" y agregaba "aquí la realidad es la realidad del concepto"38.

El concepto en lugar del sentido, entonces. Pero no es todo. En la conferencia de 1912 no se habla de correlación sino de sinfonía entre principios y problemas. Los datos de los sentidos son datos de problemas. Y el ser verdadero queda remitido al ser de la idea, "que no es ni una cosa ni un pensamiento", ni tampoco - obviamente - el sentido noemático, sino una "función, una actividad, el ser en el conocimiento [...] y el ser de las cosas no es su parecer, su ser fenoménico, sino lo que son en cuanto se conforman con su suposición" ${ }^{\prime 39}$. El logos, por su lado, es sí ley, pero ley que regula el construir - "hipótesis es fundamentación, verbo-construcción" - y no el estilo del aparecer. En este contexto el rigor metodológico halla expresión en el término "seriedad" que, bien lejos de indicar la fenomenología como ciencia estricta, según la traducción de Zubiri de strenge, es el hábito a la seriedad propio de Europa, de la que España, con el Quijote, ha dado prueba de poder formar parte, aunque se trata de una prueba inicial y no suficiente de no incompatibilidad con el idealismo ${ }^{40}$.

Ahora bien, si los pasajes recién citados proporcionan más de un motivo para reconocer la marca neokantiana y hasta natorpiana de la referencia orteguiana al pasaje del Fedón, parece que lo mismo no pudiera decirse del ejemplo del sol tal como aparece en la reseña a Hoffmann. Más bien, y teniendo en cuenta la indicación de San Martín acerca del precoz conocimiento, mediado por Schapp, de las lecciones de 1907 Ding und Raum, podríamos hablar de adquisición por parte de Ortega del problema en torno a la "posibilidad y el sentido de la percepción adecuada de cosas espaciales". Pues el propio Husserl reconocía

\footnotetext{
37 Platón, Fedón 99 d-e.

38 J. Ortega y Gasset, La "idea" de Platón, en OC, vol. VII, p. 229.

${ }^{39}$ Ibid., p. 230.

${ }^{40}$ Ibid., p. 231.
} 
la validez de la posición neokantiana según la cual la determinación definitiva del objeto queda definida como una tarea infinita. Y sin embargo, el reconocimiento de las razones fenomenológicas por las que se precisa "la conexión fenoménica, que idealmente es del todo ilimitada, para constituir una dación completa" ${ }^{\prime 1}$, más que la idea de una tarea infinita, le sugiere a Husserl que la determinación de la cosa debe estar guiada y limitada por intereses prácticoracionales ${ }^{42}$.

No se trata de una objeción porque quien escribe no está en condiciones de objetarle nada a un maestro como Javier San Martín. Lo que sí pudiera llegar a tener un cierto interés es poner de manifiesto la distinta acepción que asume el ejemplo del sol en un texto declaradamente fenomenológico como Sobre el concepto de sensación, texto que, como ya hemos recordado, ha sido eficazmente definido como "el primer texto de fenomenología en español" y en el que no sería peregrino detectar, en lugar de la tarea infinita del conocimiento, el poder de las modalizaciones que se realizan en la experiencia de exigir una modificación del sentido noemático de acuerdo con una $X$ que se configura como realidad ${ }^{43}$.

La conclusión la confío a un pasaje del libro del que aquí se han expuesto solamente algunos de sus importantes núcleos temáticos, un pasaje que, a partir de la valorización del alcance fenomenológico de la adquisición de El tema de nuestro tiempo consistente en la "reducción o conversión del mundo a un horizonte", exhibe los puntos de encuentro y de desencuentro entre Ortega y la fenomenología husserliana: "Ese sujeto viviente es lo que Husserl llama subjetividad trascendental o, mejor, vida trascendental, que, en el caso humano, somos cada uno de nosotros. Algunas de las frases de Ortega parecen escritas con precipitación, pues hay conciencias no ejecutivas, por ejemplo la conciencia que finge, toda ficción es conciencia de algo no ejecutivo. El fenomenólogo no hace otra cosa que elevar a expresión la experiencia directa muda, esa experiencia directa ejecutiva pero que por sí misma no está explicitada. La conciencia refleja no invalida el poder ejecutivo de la conciencia directa que no puede

\footnotetext{
${ }^{41}$ E. Husserl, Ding und Raum. Vorlesungen 1907, hrsg. von U. Claesges, Hua XVI, Den Haag, Nijhoff, 1973, p. 134.

42 Ibidem.

${ }^{43}$ Cf. V. Costa, L'estetica trascendentale fenomenologica. Sensibilità e razionalità nella filosofia di Edmund Husserl, Milano, Vita e Pensiero, 1999, p. 85.
} 
dejar de tener un mundo como su correlato vital. [...]. La problemática de ese mundo es que incorpora el sentido sin el cual no sería mundo vital. Entender ese carácter del mundo, de ser mundo de la vida o vital es una exigencia filosófica básica. La teoría de la razón presente en las Ideas nos indica rasgos fundamentales de esa vida subjetiva que vive el mundo no como un hecho sin más, sino como un mundo que junto con el correlato subjetivo genera la razón, porque la razón originaria está en la donación misma del mundo a la subjetividad, momento en el que se genera un nivel al que no se llega con una teoría cartesiana de que la realidad está constituida por dos sustancias yuxtapuestas, de las cuales una tiene imágenes de la otra. La fenomenología supera radicalmente este esquema. Evidentemente, cuando Ortega escribía no se disponía del contenido de la intensa actividad intelectual de Husserl, por lo que es explicable la deriva de José Ortega y Gasset. Pero ahora ya podemos poner las cosas en su lugar" ${ }^{44}$.

${ }^{44}$ Infra, pp. 173-174. 